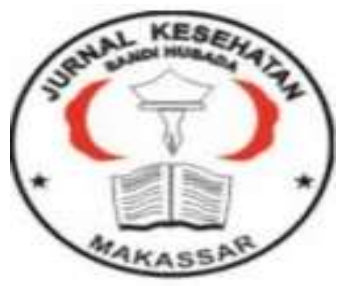

\author{
Jurnal Ilmiah Kesehatan Sandi Husada \\ https://akper-sandikarsa.e-journal.id/JIKSH \\ Vol, 10, No, 2, Desember 2019, pp 44-50 \\ p-ISSN: 2354-6093) dan e-ISSN: 2654-4563 \\ DOI: $10.35816 /$ iiskh.v10i2.105
}

\title{
Pengaruh Peran Kepala Ruangan Terhadap Kinerja Perawat Dalam Pemberian Asuhan Keperawatan Diruang Rawat Inap
}

The Influence Of The Role Of The Head Of The Room On The Performance Of Nurses In The Provision Of Nursing Care In The Inpatient Room

\section{Trimaya Cahya Mulat, ${ }^{2}$ Hartaty}

12 Ilmu Keperawatan, AKPER Sandi Karsa, Sulawesi Selatan, Indonesia

\section{Artikel info \\ Artikel history: \\ Received; 25 September 2019 \\ Revised; 20 Oktober 2019}

Accepted; 10 November 2019

\begin{abstract}
It should not be the case if the general public and the environment are constantly changing, while nursing which is part of the community has not changed in managing the life of the nursing profession. The purpose of knowing the influence of the role of the head of the room on the performance of the nurse in providing nursing care. The research method uses a type of analytic survey research with cross sectional approach. Data were collected using a questionnaire and analyzed using a linear regression test at a significant level $\mathrm{p}<0.05$. Results based on linear regression tests ( $\mathrm{T}$ test) showed that there was an influence of the role of the head of the room on the performance of implementing nurses in providing nursing care, namely; planning $(\mathrm{p}=0.007)$, organizing $(\mathrm{p}=$ $0.005)$, directing $(p=0.008)$ and supervision $(p=0.006)$. Conclusion of planning, organizing, directing, supervising the head of the room on the performance of implementing nurses in providing nursing care. Managerial capacity of the room head in managing nursing services and formulating policies on the selection system in the appointment of competency-based head of space.
\end{abstract}

\begin{abstract}
Abstrak
Menjadi hal yang aneh atau tidak semestinya terjadi, apabila masyarakat umum dan lingkungannya terus menerus berubah, sedangkan keperawatan yang merupakan bagian dari masyarakat tersebut tidak berubah dalam menata kehidupan profesi keperawatan. Tujuan mengetahui pengaruh peran kepala ruangan terhadap kinerja perawat pelaksana dalam pemberian asuhan keperawatan. Metode penelitian menggunakan jenis penelitian survey analitik dengan pendekatan cross sectional. Data dikumpulkan dengan menggunakan kuesioner serta dianalisa dengan menggunakan uji regresi linear pada tingkat signifikan $\alpha<0,05$. Hasil berdasarkan uji regresi linear (uji T) menunjukkan bahwa ada pengaruh peran kepala ruangan terhadap kinerja perawat pelaksana dalam pemberian asuhan keperawatan yaitu; perencanaan $(\rho=0,007)$, pengorganisasian $(\rho=0,005)$, pengarahan $(\rho=0,008)$ dan pengawasan
\end{abstract}


$(\rho=0,006)$. Kesimpulan perencanaan, pengorganisasian, pengarahan, pengawasan kepala ruangan terhadap kinerja perawat pelaksana dalam pemberian asuhan keperawatan. Kemampuan manajerial kepala ruang dalam mengelola pelayanan keperawatan dan mengikutsertakan kepala ruang yang belum mempunyai sertifikat dalam pelatihan manajemen bangsal perawatan serta menyusun kebijakan tentang sistem seleksi dalam pengangkatan kepala ruang yang berbasis kompetensi.

\section{Keywords:}

Nurse performance,

The role of the head

of the room,
Coresponden author:

Email: trimayacm11@gmail.com

\section{Pendahuluan}

Dalam era globalisasi ini perubahan pelayanan kesehatan/keperawatan merupakan kesatuan dalam perkembangan dan perubahan keperawatan dii Indonesia. Menjadi hal yang aneh atau tidak semestinya terjadi, apabila masyarakat umum dan lingkungannya terus menerus berubah, sedangkan keperawatan yang merupakan bagian dari masyarakat tersebut tidak berubah dalam menata kehidupan profesi keperawatan (Nursalam, 2011). Kinerja perawat sangat berhubungan dengan motivasi, supervisi dan penghargaan kerja perawat, sehingga aspek-aspek yang memengaruhi motivasi, supervisi dan penghargaan kerja perlu dikelola dengan baik untuk mendapatkan hasil kinerja perawat yang baik (Mandagi, Umboh, \& Rattu, 2015).

Terlebih adanya tuntutan pengembangan pelayanan kesehatan oleh masyarakat umum, termasuk di dalamnya adalah keperawatan, yang merupakan salah satu faktor yang harus di cermati dan diperhatikan oleh tenaga perawat, sehingga perawat mampu berkiprah secara nyata dan diterima dalam memberikan sumbangsi bagi kemanusian sesuai dengan ilmu dan kiat serta kewenangan yang dimiliki. Salah satu strategi untuk mengoptimalkan peran dan fungsi perawat dalam pealayanan keperawatan adalah pembenahan dalam manajemen keperawatan dengan harapan adanya faktor kelola yang optimal sehingga mampu menjadi wahana peningkatan keefektifan pembagian pelayanan keperawatan sekaligus lebih menjamin kepuasan pasien terhadap kinerja pelayanan keperawatan. Dengan kata lain bahwa diperlukannya manajemen yang baik untuk mencapai hasil yang optimal dalam pemberian asuhan keperawatan (Nursalam, 2014).

Manajemen merupakan pendekatan yang dianamis dan proaktif dalam menjalankan suatu kegiatan diorganisasi. Dalam manajemen tersebut mencakup kegiatan koordinasi dan supervise terhadap staf, sarana dan prasarana dalam mencapai tujuannya. Manajemen keperawatan sebagai proses bekerja melalui anggota staf untuk memberikan asuhan keperawatan secara professional. Proses manajemen keperawatan sejalan dengan keperawatan sebagai salah satu metode pelaksanaan asuhan keperawatan secara professional diharapkan keduanya saling menopang (Nursalam, 2014).

Peran perawat kepala ruangan dalam aplikasi metode tim diarahkan pada keterampilan dan minat yang dimilikinya. Disamping itu, perawat kepala ruangan harus mampu ,mengoptimalkan fungsi tim melalui orientasi anggota tim dan pendidikan berkelanjutan, mengkaji kekmpuan anggota tim dan membagi tugas sesuai dengan keterampilan anggotanya. Hal yang tidak kalah pentingnya adalah perawat kepala ruangan harus mampu sebagai model peran(Arwani, 2006). Pengawasan merupakan suatu proses untuk mengetahui apakah pelaksanaan kegiatan/pekerjaan sesuai dengan rencana, pedoman, ketentuan, kebijakan, tujuan, dan sasaran yang sudah ditentukan sebelumnya (Suarli S \& Bahtiar, 2010). 
Kinerja SDM merupakan istilah yang berasal dari kata job performance atau actual performance (prestasi kerja atau prestasi sesungguhnya yang dicapai seseorang). Definisi kinerja karyawan yang dikemukakan (Marquis, 2010) adalah : perbandingan hasil yang dicapai dengan peran serta tenaga kerja persatuan waktu (lazimnya per jam).

\section{Metode}

Metode yang digunakan dalam penelitian ini adalah Desain penelitian ini merupakan Survei Analitik yang bertujuan untuk melihat pengaruh peran kepala ruangan terhadap kinerja perawat pelaksana dalam pemberian asuhan keperawatan diruang rawat inap Rumah Sakit Salewangeng Maros dengan menggunakan pendekatan Cross Sectional yaitu jenis penelitian yang menekankan pada waktu pengukuran/observasi data variabel independen dan dependen hanya satu kali pada suatu saat (Sugiyono, 2011). Adapun sumber data yang dipergunakan dalam penelitian ini adalah sumber data primer dan sumber data sekunder, yang diuraikan sebagai berikut: Sumber Data Primer, data primer yakni data yang diperoleh di lapangan yang didapat dari responden. Dengan menggunakan analisis bivariate untuk melihat hubungan dari tiap variabel independen yang meliputi peran kepala ruangan dengan perawat pelaksana maka dilakukan uji statistik analisis regresi linear berganda dengan tingkat kemaknaan $\alpha<0.05$.

\section{Hasil Dan Pembahasan}

Tabel. 1 Analisis Nilai koefisien regresi linear berganda

\begin{tabular}{lcccl}
\hline \multicolumn{1}{c}{ Variabel } & Koefisien & $\mathbf{T}_{\text {hitung }}$ & $\mathbf{T}_{\text {tabel }}$ & Keterangan \\
\hline (Constant) & 5,554 & & & \\
\hline Perencanaan & 0,437 & 2,794 & 1,993 & Hipotesis diterima \\
\hline Pengorganisasian & 0,385 & 2,915 & 1,993 & Hipotesis diterima \\
\hline Pengarahan & 0,608 & 2,743 & 1,993 & Hipotesis diterima \\
\hline Pengawasan & 1,347 & 2,822 & 1,993 & Hipotesis diterima \\
\hline
\end{tabular}

Berdasarkan hasil uji statistik menggunakan regresi linear (uji T) diperoleh nilai $\rho$ 0,007< 0,05 atau nilai $t_{\text {hitung }} 2,794>t_{\text {tabel }}$ 1,993 dengan demikian disimpulkan perencanaan berpengaruh signifikan terhadap kinerja perawat pelaksana dalam pemberian asuhan keperawatan. Hasil penelitian sesuai dengan penelitian (Rohmawati, 2006), yang mengatakan bahwa ada pengaruh signifikan antara pelaksana asuhan keperawatan yang baik dengan fungsi kepala ruangan yang efektif, dan sejalan juga dengan penelitian yang dilakukan oleh Parmin (Mandagi et al., 2015), bahwa terdapat pengaruh yang signifikan antara fungsi manajemen perencanaan kepala ruangan dengan kinerja perawat pelaksana.

Menurut asumsi peneliti, fungsi perencanaan bila dilaksanakan dengan baik akan memudahkan usaha yang dilakukan dalam mencapai tujuan yang diinginkan. Selain itu, perencanaan yang optimal dapat membantu manajer dan staf dalam mengetahui tujuan yang jelas dari suatu perencanaan yang dibuat. Hal ini didukung oleh (Gillies (1989) dalam Arwani, 2006), yang mengatakan bahwa fungsi perencanaan sebaiknya dilakukan oleh kepala ruangan secara optimal agar dapat memberikan arahan kepada perawat pelaksana, mengurangi dampak perubahan yang terjadi dan memperkecil pemborosan atau kelebihan. Fungsi perencanaan pelayanan dan asuhan keperawatan di ruang rawat inap yang dilaksanakan oleh kepala ruangan adalah sebagai pemikiran atau konsep tindakan tertulis seorang manajer (Swansburg RC, 2016). Hasil penelitian menunjukkan persepsi perawat pelaksana tentang fungsi perencanaan kepala ruangan sebagian besar dalam kategori baik $(63,2 \%)$, hal ini menunjukkan bahwa fungsi 
perencanaan kepala ruangan sangat membantu dalam pemberian asuhan keperawatan (pengkajian, merumuskan diagnosa keperawatan, membuat intervensi, melakukan implementasi dan evaluasi).

Berdasarkan hasil uji statistik menggunakan regresi linear (uji T) diperoleh nilai $\rho 0,005<$ 0,05 atau nilai $t_{\text {hitung }} 2,915>t_{\text {tabel }} 1,993$ dengan demikian disimpulkan pengorganisasian berpengaruh signifikan terhadap kinerja perawat pelaksana dalam pemberian asuhan keperawatan. Hal ini sejalan dengan hasil penelitian yang dilakukan oleh (Rohmawati, 2006), bahwa ada pengaruh signifikan antara pelaksanaan asuhan keperawatan yang baik dengan fungsi pengorganisasian kepala ruangan, demikian pula hasil penelitian oleh (Nainggolan, 2010), bahwa ada pengaruh yang bermakna antara pengorganisasian kepala ruangan dengan kinerja perawat pelaksana.

Kepala ruangan sebagai koordinator kegiatan perlu menciptakan kerja sama yang baik, pemberian tanggung jawab dan kewenangan yang sesuai serta saling menunjang satu sama lain, sehingga tercipta suasana kerja yang menyenangkan, selain itu dengan tersedianya fasilitas yang mendukung dan menunjang kelancaran tugas sehingga perawat dapat lebih bersemangat dalam melakukan pekerjaannya khususnya dalam memberikan asuhan keperawatan secara menyeluruh(Marquis,2010). Kemampuan manajerial dalam fungsi pengorganisasian diharapkan dapat membantu perawat pelaksana untuk melaksanakan asuhan keperawatan kepada klien dengan benar dan baik. Adapun pengorganisasian adalah keseluruhan pengelompokan orangorang, alat-alat, tugas-tugas kewenangan dan tanggung jawab sehingga tercipta suatu organisasi yang dapat digerakkan sebagai suatu kesatuan dalam rangka mencapai tujuan yang telah ditetapkan (Swansburg RC, 2016). Hasil penelitian menunjukkan persepsi perawat pelaksana tentang fungsi pengorganisasian kepala ruangan sebagian besar dalam kategori baik $(60,5 \%)$, hal ini ini menunjukkan bahwa fungsi pengorganisasian kepala ruangan memberikan makna dalam membantu pelaksanaan asuhan keperawatan, dalam fungsi pengorganisasian terdapat pembagian tugas dan tanggung jawab untuk mencegah, mengurangi atau mengoreksi masalahmasalah yang diidentifikasi pada tahap pengkajian sampai pada tahap evaluasi. Dari uraian tersebut dapat dijelaskan bahwa pengorganisasian berpengaruh terhadap kinerja perawat dimana pelayanan yang diorganisasikan dan dilakukan dengan pembagian kerja yang jelas dapat membantu kepala ruangan dalam memperbaiki kinerja yang ada. Keberadaan pengorganisasian memberikan bantuan secara tehnis pada perawat pelaksana dalam melaksanakan tugas sebagai pemberi asuhan keperawatan meliputi pengkajian, menentukan prioritas, menentukan kriteria hasil, menentukan rencana tindakan, dan dokumentasi.

Berdasarkan hasil uji statistik menggunakan regresi linear (uji T) diperoleh nilai $\rho 0,008<$ 0,05 atau nilai $t_{\text {hitung }} 2,743>t_{\text {tabel }}$ 1,993 dengan demikian disimpulkan pengarahan berpengaruh signifikan terhadap kinerja perawat pelaksana dalam pemberian asuhan keperawatan. Hal ini sejalan dengan hasil penelitian yang dilakukan oleh (Arifi M, 2005), bahwa terdapat pengaruh yang signifikan terhadap fungsi pengarahan kepala ruangan dengan kinerja perawat pelaksana, demikian pula hasil penelitian oleh (Rohmawati, 2006), mengatakan bahwa ada pengaruh signifikan antara pelaksanaan asuhan keperawatan yang baik dengan fungsi pengarahan kepala ruangan yang efektif. Kemudian hasil penelitian yang dilakukan oleh (Nainggolan, 2010), bahwa terdapat pengaruh antara fungsi manajemen pengarahan kepala ruangan dengan kinerja perawat pelaksana.

Asumsi peneliti fungsi pengarahan adalah membuat perawat atau staf melakukan apa yang diinginkan dan harus mereka lakukan. Kepala ruanga dalam memberikan pengarahan melalui: saling memberi motivasi, membantu pemecahan masalah, melakukan pendelegasianj, menggunakan komunikasi yang efektif, melakukan kolaborasi dan koordinasi.

Hal ini sejalan dengan yang diungkapkan (Swansburg RC, 2016), bahwa di dalam fungsi pengarahan, manajer memiliki deskripsi pekerjaan sebagai berikut: memberitahu serta menjelaskan tujuan yang ingin dicapai kepada bawahan, membimbing serta mengembangkan para bawahan, memberikan hak untuk mendengarkan, memuju, member sanksi dan 
penghargaan. Hal yang sama juga dikemukakan oleh (Nursalam, 2014), menyatakan bahwa tugas pokok seorang kepala ruangan sebagai pengarahan yaitu memberi pengarahan tentang penugasan, memberi motivasi, menginformasikan hal-hal yang dianggap penting dan berhubungan dengan asuhan keperawatan pasien serta membimbing bawahan yang mengalami kesulitan dan meningkatkan kolaborasi. Peran pengarrahan kepala ruangan sangat membantu perawat pelaksana dalam memberikan asuhan keperawatan, hal ini bahwa peran pengarahan membantu perawat dalam mencapai tujuan yang telah ditetapkan pada ppemberian asuhan keperawatan yang mencakup peningkatan kesehatan, pencegahan penyakit, pemulihan kesehatan, dan memfasilitasi koping. Selama tahap pelaksanaan, perawat terus melakukan pengumpulan data dan memilih tindakan keperawatan yang paling sesuai dengan kebutuhan klien. Berdasarkan uraian tersebut dapat dijelaskan bahwa peran pengarahan kepala ruangan sangat penting dalam mendukung terciptanya kinerja perawat yang baik dalam pemberian asuhan keperawatan, artinya bahwa variabel pengarahan memiliki pengaruh yang positif dan signifikan terhadap kinerja perawat pelaksana dalam pemberian asuhan keperawatan di RSUD Salewangan Maros.

Berdasarkan hasil uji statistik menggunakan regresi linear (uji T) diperoleh nilai $\rho$ 0,006 < 0,05 atau nilai thitung 2,822 $>t_{\text {tabel }}$ 1,993 dengan demikian disimpulkan pengawasan berpengaruh signifikan terhadap kinerja perawat pelaksana dalam pemberian asuhan keperawatan. Hal ini sejalan dengan hasil penelitian yang dilakukan oleh (Argapati, 2016), bahwa ada pengaruh fungsi pengawasan kepala ruangan dengan kinerja perawat, demikian pula hasil penelitian oleh (Dumauli, 2018), menerangkan bahwa ada pengaruh yang bermakna antara pelaksanaan fungsi pengawasan kepala ruangan dengan kinerja perawat pelaksana, Kemudian hasil penelitian yang dilakukan oleh (Nainggolan, 2010), terdapat pengaruh yang signifikan antara fungsi manajemen pengawasan kepala ruangan dengan kinerja perawat pelaksana. Pengawasan yang efektif akan meningkatkan kepuasan kerja, motivasi dan hasil yang berkualitas. Dengan pengawasan memungkinkan rencana yang telah dilaksanakan oleh sumber daya secara efektif dan efisien sesuai dengan standar yang ditetapkan (Marquis, 2010). Menurut teori x dari Mc Gregor dalam (Hasibuan.M, 2001), untuk memotivasi karyawan harus dilakukan cara pengawasan yang ketat, dipaksa dan diarahkan supaya mereka bekerja sungguh-sungguh. Fungsi pengawasan kepala ruangan dalam pelayanan keperawatan dapat dilaksanakan dengan kegiatan supervis langsung atupun tidak langsung. Selain itu jiga dilaksanakan penilaian pelaksanaan asuhan keperawatan, memperhatikan kemajuan dan kualitas asuhan keperawatan, memperbaiki kelemahan/kekurangan asuhan keperawatan, meningkatkan pengetahuan dan keterampilan perawat dalam asuhan keperawatan, dan menggunakan standar untuk menilai asuhan keperawatan(Nursalam, 2014).

Asumsi peneliti, dalam melaksanakan penilaian terhadap pelaksanaan asuhan keperawatan perlu melihat tujuan dan kriteria hasil yang telah ditentukan sebelumnya dengan kondisi atau keadaan klien yang diberikan asuhan keperawatan oleh perawat pelaksana sebelum memberikan masukan apakah pelaksanaan asuhan keperawatan tersebut dihentikan atau dilanjutkan. Oleh karena itu saat melakukan pengawasan perlu memperhatikan hubungan yang sejajar, mendatar atau horisontal dengan perawat pelaksana dan memandang sebagai rekan kerja atau teman sejawat. Sehingga peran pengawasan bila dilaksanakan dengan baik akan memberikan dampak terhadap kinerja perawat pelaksana. 


\section{Kesimpulan}

Berdasarkan hasil penelitian menunjukkan bahwa melaksanakan penilaian terhadap pelaksanaan asuhan keperawatan perlu melihat tujuan dan kriteria hasil yang telah ditentukan sebelumnya dengan kondisi atau keadaan klien yang diberikan asuhan keperawatan oleh perawat pelaksana sebelum memberikan masukan apakah pelaksanaan asuhan keperawatan tersebut dihentikan atau dilanjutkan. Oleh karena itu saat melakukan pengawasan perlu memperhatikan hubungan yang sejajar, mendatar atau horisontal dengan perawat pelaksana dan memandang sebagai rekan kerja atau teman sejawat. Sehingga peran pengawasan bila dilaksanakan dengan baik akan memberikan dampak terhadap kinerja perawat pelaksana. Peran kepala ruangan dalam kategori baik meliputi (perencanaan, pengorganisasian, pengarahan dan pengawasan) diharapkan dapat terus ditingkatkan sehingga fungsi-fungsi manajerial dapat berjalan efektif.

\section{Ucapan Terima Kasih}

Direktur dan Lembaga penelitian dan pengabdian kepada masyarakat Akademi Keperawatan Sandi Karsa.

\section{Daftar Rujukan}

Argapati. (2016). Gambaran Kepuasan Kerja Perawat Rawat Inap Rumah Sakit Stella Maris Makassar. Jurnal Kesehatan.

Arifi M. (2005). Hubungan Kemampuan Manejerial Kepala Ruangan dengan Kinerja Perawat Pelaksana di Ruangan Rawat Inap RSI PKU Muhammadiyah \{Pakajangan. Tesis. Program Pasca Sarjana FIK-UI.

Arwani, dkk. (2006). Manajemen Bangsal Keperawatan. Jakarta: EGC.

Dumauli. (2018). Hubungan Persepsi Perawat Pelaksanan Tentang pelaksanaan fungsi MPKP RSUD Budi Asih Jakarta. Program Pasca Sarjana FIK - UI.

Gillies (1989) dalam Arwani. (2006). Manajemen Bangsal Keperawatan. Jakarta: EGC.

Hasibuan.M. (2001). Manajemen Sumber Daya Manusia edisi Revisi. Jakarta: Bumi Aksara.

Mandagi, F. M., Umboh, J. M. L., \& Rattu, J. A. M. (2015). Analisis Faktor - Faktor Yang Berhubungan Dengan Kinerja Perawat Dalam Menerapkan Asuhan Keperawatan Di Rumah Sakit Umum Bethesda Gmim Tomohon. Jurnal e-Biomedik (eBm), 3(3), 1-11. Diambil dari

https://ejournal.unsrat.ac.id/index.php/ebiomedik/article/view/10479/10066

Marquis, L. dan H. C. (2010). Kepemimpinan dan Manajemen Keperawatan Teori dan Aplikasi. Jakarta: EGC.

Nainggolan, M. J. (2010). Pengaruh Pelaksanaan Supervisi Kepala Ruangan terhadap Kinerja Perawat Pelaksana di Rumah Sakit Islam Malahayati Medan.

Nursalam. (2011). Manajemen keperawatan' Aplikasi Dalam Praktik keperawatan Profesional. Edisi 3. Jakarta: Salemba Medika.

Nursalam. (2014). Manajemen keperawatan' Aplikasi Dalam Praktik keperawatan Profesional. Edisi 3. Jakarta: Salemba Medika.

Pengaruh Persepsi Perawat Pelaksana Tentang Fungsi Manajerial Kepala Ruang Terhadap Pelaksanaan Manajemen Asuhan Keperawatan Di Ruang Rawat Inap RSUD Dr. Amino

Trimaya Cahya Mulat,Hartaty, The Influence Of The Role Of The Head Of The Room On The Performance Of Nurses In The Provision Of Nursing Care In The Inpatient Room, JIKSH, Vol.10, No2, 2019 
Gondohutomo Semarang. (2016). Tesis.

Rohmawati, T. (2006). Hubungan fungsi manajemen kepala ruangan menurut persepsi perawat pelaksanan dan karakteristik individu dengan pelaksanaan asuhan keperawatan diRuang Rawat Inap RSUD Sumedang Tesis. Tesis PPS FIK - UI.

Suarli S \& Bahtiar, S. (2010). Manajemen keperawatan dengan pendekatan Praktis. Jakarta: ErLangga.

Sugiyono. (2011). Metode penelitian kuantitatif dan kualitatif. Bandung: Alfabeta. 